\title{
Reward System: A Tool for Employee Retention as Observed from the Banking Sector in Port Harcourt
}

\author{
Ovunda Amadi ${ }^{1}$, Isaac Zeb-Obipi ${ }^{2}$, Sorbarikor Lebura ${ }^{2}$, Godwin Poi $^{3}$ \\ ${ }^{1}$ OK Foods Ltd., Matori Mushin, Lagos, Nigeria \\ ${ }^{2}$ Department of Management, Faculty of Management Sciences, Rivers State University, Port Harcourt, Nigeria \\ ${ }^{3}$ Department of Business Administration, Faculty of Social and Management Sciences, University of Africa, Toru-Orua, Nigeria
}

Email address:

sorbarikor.lebura@ust.edu.ng (S. Lebura)

\section{To cite this article:}

Ovunda Amadi, Isaac Zeb-Obipi, Sorbarikor Lebura, Godwin Poi. Reward System: A Tool for Employee Retention as Observed from the Banking Sector in Port Harcourt. Journal of Human Resource Management. Vol. 9, No. 2, 2021, pp. 50-57.

doi: $10.11648 /$ j.jhrm.20210902.14

Received: May 27, 2021; Accepted: June 10, 2021; Published: June 25, 2021

\begin{abstract}
Workers are considered as strategic assets in any organization because the accomplishment of an organization's objectives largely depends on the employees, so employers always strive to ensure that they retain their best employees. However, such employees can only become strategic assets if they are motivated to deliver on their tasks and specific assignments. Therefore, it is important to identify factors which motivate employees for the achievement of set organisational goals. The objective of this study is to investigate the extent to which organisational reward systems impact on employee retention in the banking industry in Port Harcourt, Nigeria. To achieve this objective, this study has examined the relationship between remuneration, promotion and recognition as the dimensions of reward systems and employee retention. In terms of methodology, the survey research design was utilized, with the structured questionnaire used as the primary data collection method. The generated data was analyzed using descriptive and inferential statistics as well as the spearman's test statistics. The results revealed that there is a positive relationship between remuneration, promotion, and recognition as dimensions of reward systems and employee retention. The conclusion reached is that for banks in Port Harcourt to retain their best employees, they would need to improve their reward systems, specifically the remuneration, promotion and recognition that they offer their employees. It is recommended that there should be further empirical research to test the applicability of the findings of this study in other sectors of the Nigerian economy as well as the relationship between other dimensions of reward systems and employee retention.
\end{abstract}

Keywords: Promotion, Recognition, Remuneration, Retention, Reward

\section{Introduction}

Employers have increasingly identified the important role of workers in their workstations and the necessity to attract, increase their morale and keep clever employees. It is argued that that retaining good employees (i.e. those that positively support and add to the advancement of the firm) is deduced to be absolutely connected with reaching organizational objectives/goals as well as developing competitive advantage for the firm [3]. One major means by which this objective is attained is by rewarding workers, which is related with the inspiration of the organizational workforce for enhanced performance. However, what type and blend of rewarding tools utilized is challenging for every organization. Reward is a key tool used to increase employees' commitment in the workplace, which leads to an improvement in their work performance [20]. Employees are appropriately considered as the most important resource for any organization even in financial business organizations [32].

The reason behind the utilization of reward framework for workers is that it persuades employees to give their best, and in turn become fulfilled as far as both their money related and non-monetary needs are met. It is also argued that the inability of corporations to do so would lead to workers being enticed to leave the organization [6]. On one hand, representatives are inclined to accept characteristic rewards regarding applause and acknowledgment for certain work achievements, while different workers are content with outward reward as far as bills are paid [26, 37]. The present 
business scene is changing quickly because of certain elements, for example, globalization, responsiveness to clients, expanding income and diminishing costs, and others; all of which combine to make the present business environment unpredictable. These business conditions and extraordinary challenges have also created a level of uncertainty in the minds of workers as to what and how their future will be if they remain with their employing organizations. The preceding premise calls for key and pragmatic methodology towards worker advancement, commitment, and effective worker utilization in organizations. Contemporary organizations, particularly service businesses, need to discover better methodologies for inspiring, training and keeping a dependable workforce.

Reward frameworks are ostensibly at the core of worker performance. This statement is hinged on the understanding that reward frameworks have the intensity of causing more elevated levels of performance in corporations through the stimulation and guidance of workers towards organizational objective achievement [16]. Workers are the most valuable resource in any organization, and their abilities to function in such a defined manner so as to reach organizational goals and objectives is a function of the reward system prevalent in the organization and also the working condition in the organization. This nature-nurture point of view of clarifying the markers of worker performance underscores the imperativeness of reward frameworks as basic piece of organizational environments. In this light, it is informational to attest that well remunerated workers are more likely to feel esteemed and treasured by their corporations. In spite of the seemingly imperative nexus between reward frameworks and worker performance in corporations, it is troubling to note that the much-wanted worker performance that is a basic contribution for economically expanding organizational profitability is to a great extent missing when the workforce are not incentivized and motivated towards such organizational objective and goal. Also, the genuine achievement of any corporation starts from the workers' readiness to utilize their innovativeness, capabilities and know-how toward their corporations' development and advancement [10], and as such, keeping such workers becomes a major organizational strategy for continuous improved performance.

Studies have indicated that the cost of losing a talented employ far outweighs whatever costs are attached to ensuring that such employees are retained within the organisation $[55,58,59]$. It has also been noted that employee turnover may not only cost the company money and time, but breaks an existing work relationship that was possibly for the common good of the organization. Nonetheless, not all turnovers are harmful since they also help attract different employees and new concepts. Initially, many employees are a "cost" for the corporation, but later, with the requisite aptitude techniques, they turn out to be more appreciated. It has been argued that retaining the best employees can be crucial, as this will determine if the operations in the organization will go smoothly and efficiently and if an organization maintains a competitive advantage [47]. Based on this premise, retention is something that organizations are interested in.

Therefore, this paper examines how reward system can influence employee retention as conceptualized below.

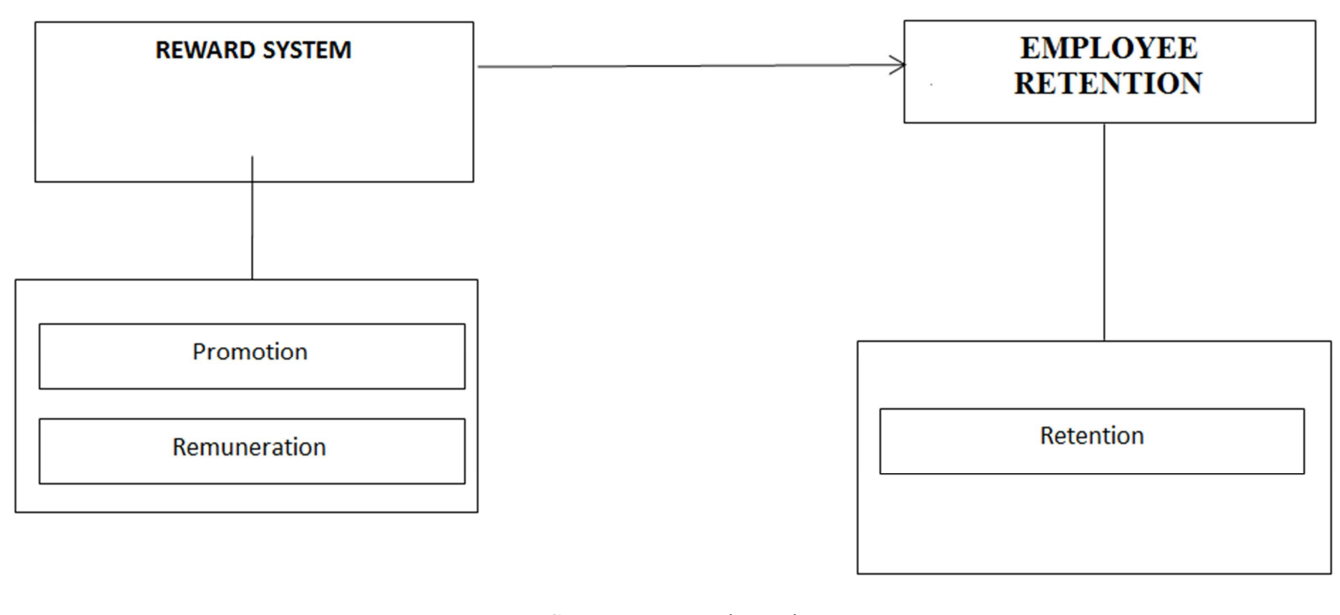

Source: Research Desk

Figure 1. Conceptual Framework.

Research Hypotheses

$\mathrm{Ho}_{1}$ : There is no significant relationship between promotion and employee retention in commercial banks in Port Harcourt.

$\mathrm{Ho}_{2}$ : There is no significant relationship between remuneration and employee retention in commercial banks in Port Harcourt.

\section{Literature Review}

\subsection{Reward System}

Reward can be defined as an agent external to the employee, which is administered in response to the performance of a desired act or task by the employee [56]. It is also regarded as those external influences that are managed 
when a job or task has information and control so that the task is successfully implemented [57].

Each current organization has some type of reward framework, regardless of whether it is blunt or not, it exists [24]. Well-rewarded employees always feel valued by the organisation, as they are aware that such rewards are tied to work done [54] and they have been categorized into intrinsic or extrinsic [46]. The latter type of reward which is the concentration of this paper can be further expressed through either financial or non-financial rewards. The financial reward, which can also be deemed as money related is typically a variable pay, isolated from the regular compensation and it is gotten as a result of exceptional performance or as a consolation. It can be either exclusively individually-based meaning that the performing individual gets it or group-based indicating that it is given to a group or team.

The conditions to acquire this reward ought to be set ahead of time and the performance should be quantifiable [24]. There exists an assortment of reasons for a reward framework, with the major reason being to inspire workers to perform better. Accordingly, some organizations design a reward framework not only for improved employees' performance, but also as a means to keep good committed workforce (retention strategy) [4]. For a reward framework to be motivating and well enticing, it ought to fulfil certain criteria; give value to the receiver, be justifiable, be convenient [27].

Scholars have argued that organization's remuneration component assumes a fundamental part in inspiring workers $[1,4,17,24]$. Diverse sorts of rewards are basic factors that illuminate certain work points that add to the organization as best worker performance. Reward system plays a vital part in how employees see the pay framework within the work environment [25]. There have been various views expressed on the impact of rewards such as that diverse reward offerings improve worker performance $[1,53]$, monetary and non-monetary rewards are essential for high occupation performance [17]. It also refers to the collection of brain structures that try to control and regulate behaviour by inducing pleasure [2].

\subsubsection{Intrinsic Reward}

Intrinsic reward concerns the psychological development of employees [45], with intangible benefits that include characteristics such as autonomy, feedback and decisionmaking participation [21]. The intrinsic reward system is intentionally created to appreciate employees in the form of self-esteem and is related to their feeling of achievement and growth within the organization. Employees feel satisfied when they have accomplished something worthwhile at work and are appreciated by the organization [31]. Intrinsic rewards are regarded as those rewards that are innate inside a worker, or inside employment itself [35]. It is also deemed to incorporate employees' ability, recognition, trust and achievement [18].

Recognition: One dimension of intrinsic reward is recognition, which has been characterized as the capacity of a senior administrator or manager to distinguish and acknowledge a worker, for a positive thing done over the span of their work [36]. It is important that business administrators observe and distinguish their employees for their praiseworthy performance, even as it is contended that such recognition acts as an intrinsic inspiration that is fundamental in driving employees to feel esteemed [43]. In an investigation conducted in the Singaporean hospitality industry, it was found the presence of an immediate connection between employee recognition and worker performance [22]. The research noted that where managers gave employees recognition for functions admirably executed, there was high improvement in performance. Employees were asked to indicate why recognition by their administrators was instrumental to their performance improvement, to which majority of the respondents (72\%) demonstrated that they felt esteemed by their supervisors, and felt their work made a difference.

Promotion: Another dimension that shows the existence of intrinsic reward is promotion. Promotion is defined as a movement within an organization from one position to another that involves either an increase in pay, responsibilities, or an increase in status [39]. He further noted that promotion is done based on improved worker performance over time, even as certain promotions result in workers overseeing the tasks of other employees. Outwardly, a promotion moves a worker's activity up one level on an organizational diagram. The promotion of employees also leads to increased engagement of such employees [52], as they are given more responsibilities in line with their new positions. A promotion is seen as alluring by workers in view of the effect that a promotion has on pay, authority, duty, and the capacity to exert more extensive authority in basic leadership setups. A promotion also ensures that there is some level of career prospect and change in status [51] for the promoted employee which is like signposting of the employer's regard for the promoted employee.

Promotion is a type of acknowledgment for workers who make proficient and viable work commitments. Therefore, a promotion emerges in organizations since repeated promotions consistently place a worker in a management level. Promotion is an increase of a worker or an employee in an organization to a better job, compared with the previous based on the responsibilities, achievement, facilities, status, demands for proficiency, and the addition of wages or salaries as well as other allowances [5]. It is also noted that promotions are marked by some indicators, which include but are not limited to increased responsibilities, increased duties, enhanced rights and improved authority [6]. All contributors in an organization must be qualified for advancements that will consequently reward their job as donors.

\subsubsection{Extrinsic Rewards}

Rewards are deemed extrinsic because they are external to completing the work itself and are controlled by people other 
than the employee [48]. There are different dimensions to extrinsic rewards but this paper uses just remuneration, even as it has been previously argued that extrinsic rewards are usually financial or tangible rewards given to employees, such as pay raises, bonuses, and benefits [48].

Remuneration: This is defined as pay or reward given to individuals for work done [7]. The indicators of remuneration were further identified as basic salary, wages, health schemes, pension schemes, transport allowances, overtime allowances and responsibility allowances. Remuneration can also be referred to as monetary or financial benefits in form of salaries, wages, bonuses, incentives, allowances and benefits that are accrued or given to an employee or group of employees by the employer (firm) as a result of services rendered by the employee(s), commitment to the organization or reward for employment [40]. Pay is also seen as a means of job satisfaction, which can be used to influence employee performance [9]. They further noted that organizations use their prevailing pay system as a tool in motivating employees to attain job satisfaction. To them, net pay, wages and salaries are urgent means of achieving a sum standard of living.

In other words, the money workers earn is important to them not only financially for what it buys, but also physiologically for what it will provide them in terms of status and definition, both within and outside the organization [14]. Since money presents a quantifiable measure of their worth, employees are very sensitive about the amount of pay they receive in return for their contributions on the job, and how the amount compares with what other employees are receiving for their contributions [34]. Employees therefore want their wages to be equitable both in terms of what is being demanded of them on the job and in terms of what their colleagues are paid in return for the demands of their objective jobs [9].

Remuneration can be regarded as any type of compensation or payment that an individual or employee receives as payment for their services or the work that they do for an organization [23]. This could include whatever base salary such an employee receives, along with other forms of payment that accrue during the course of their work, which includes expense account funds, bonuses, and stock options. For most employees, pay has a direct bearing on their standard of work and upon the status and recognition and this also constitutes a quantitative part of their relative worth in comparison with fellow employees [48].

\subsection{Employee Retention}

The retention of employees can be influenced through the initiation of balanced and defined goals and objectives in an organization. Retention is described as the effort made by employers to make good policies aimed at ensuring that talented employees are kept in the organization to achieve set organizational goals and objectives, thereby leading to success [19]. Considering this, employers take proactive steps to prevent their key employees from switching jobs [12], and these steps vary from one organization to another. These steps could be regarded as good retention strategies that lead to greater time spent by employees in the organization and also motivates them to do their job dedicatedly $[13,28,29,50]$. The expertise of talented employees as made up of their knowledge, skills and experience makes them of high worth to their organizations [15], leading to their special treatment by organizations.

It is also suggested that alleged backing from the organization sturdily influences work contentment and wage earner commitment in organizations [41]. The change in behaviour of employees to meet up "with the organization's desired corporate culture influences employee retention" [49]. In addition to desired corporate culture, organizations must create a positive work environment conducive for work in order to retaining their talented workforce [11]. Also, "good and successful organizations respect their employees and try to make policies more flexible for the betterment of employees so that their level of employee engagement and high level of retention can be achieved" [38].

It was found that one of the utmost potent indication tools used in predicting retention based on time includes confident know-hows in comparison to the organizational guidelines and approach of the company towards employees [29]. It has been pointed out that fiscal awards could "be a top motivator for employee retention, a fun workplace" and adaptable timetables were additions [44]. A study on the factors that promote retention has noted that good salary and benefit package helps organizations, but the decision to stay with the organization is dependent on how employers respond to their growth within the organization [42]. They further stressed that when employees are more committed in challenging jobs then they are more likely to stay with the organization.

\section{Methodology}

This study was based on a sample size of 63 workers from ten banks in Port Harcourt. The paper adopted the survey research design, and the stratified sampling technique was used. Each of the studied banks was sent copies of pre-designed questionnaire for management employees (Top managers, middle managers, junior managers and supervisors). The questionnaire consisted of questions measuring promotion, remuneration and employee retention on a 5-point Likert scale (where, $5=$ very high extent, $4=$ high extent, $3=$ moderate extent, 2 = low extent, 1 = very low extent), showing the level of perceptions with the content of each item. Before starting the fieldwork, the questionnaire was pre-tested for validity and reliability in order to ensure that the items included were comprehensible to the recipients. This was achieved with the cooperation of academics as well as the use of the test-retest method of reliability.

The Spearman rank order correlation coefficient was used for data analysis, with this choice being influenced by the understanding that this test statistic is most appropriate when a test aims to evaluate the strength of relationships between variables. The $r$ value was used to represent this relationship to either be negative or positive. 


\section{Findings}

There was analysis of all the dimensions (promotion and remuneration) with the measure retention respectively using the Spearman rank order correlation coefficient statistical tool via the SPSS software.

\subsection{Hypothesis 1}

$\mathrm{Ho}_{1}$ : There is no significant relationship between promotion and employee retention in the banking industry.

The test statistics used in testing the above hypothesis is the spearman's rank order correlation coefficient. The computation of the value of the test statistics as done using
SPSS is represented in the table below.

The statistics gave an $r$ value of 0.980 which it gives from our scaled list a highly marked correlation between the variables under investigation. The probability value from the table is 0.000 , which implies that the variables are statistically significant. Therefore, we rejected the null hypothesis which states that "there is no significant relationship between promotion and employee retention in the banking industry in Port Harcourt", and accept the alternative hypothesis, "there is significant relationship between promotion and employee retention in the banking industry in Port Harcourt".

Table 1. Spearman rank order calculation.

\begin{tabular}{|c|c|c|c|c|}
\hline \multicolumn{5}{|l|}{ Correlations } \\
\hline & & & Promotion & Retention \\
\hline \multirow{6}{*}{ Spearman's rho } & \multirow{3}{*}{ Promotion } & Correlation Coefficient & 1.000 & $.980^{* *}$ \\
\hline & & Sig. (2-tailed) & & .000 \\
\hline & & $\mathrm{N}$ & 63 & 63 \\
\hline & \multirow{3}{*}{ Retention } & Correlation Coefficient & $.980^{* *}$ & 1.000 \\
\hline & & Sig. (2-tailed) & .000 & . \\
\hline & & $\mathrm{N}$ & 63 & 63 \\
\hline
\end{tabular}

**. Correlation is significant at the 0.01 level (2-tailed).

Source: Survey data, 2020.

\subsection{Hypothesis 2}

$\mathrm{Ho}_{2}$ : There is no significant relationship between remuneration and employee retention in the banking industry in Port Harcourt.

The table below shows the computed value for the above hypothesis using Spearman rank order correlation coefficient through SPSS.

Table 2. Spearman rank order calculation.

\begin{tabular}{|c|c|c|c|c|}
\hline \multicolumn{5}{|l|}{ Correlations } \\
\hline & & & Remuneration & Retention \\
\hline \multirow{6}{*}{ Spearman's rho } & \multirow{3}{*}{ Remuneration } & Correlation Coefficient & 1.000 & $.920^{* *}$ \\
\hline & & Sig. (2-tailed) & & .000 \\
\hline & & & 63 & 63 \\
\hline & \multirow{3}{*}{ Retention } & Correlation Coefficient & $.920^{* *}$ & 1.000 \\
\hline & & Sig. (2-tailed) & .000 & . \\
\hline & & $\mathrm{N}$ & 63 & 63 \\
\hline
\end{tabular}

**. Correlation is significant at the 0.01 level (2-tailed).

Source: Survey data, 2020.

The statistics gave an $r$ value of 0.920 which it gives from our scaled list a highly marked correlation between the variables under investigation. The probability value from the table is 0.000 , which implies that the variables are statistically significant. Therefore, we rejected the null hypothesis which states that "there is no significant relationship between remuneration and employee retention in the banking industry in Port Harcourt", and accept the alternative hypothesis, "there is significant relationship between remuneration and employee retention in the banking industry in Port Harcourt',

These findings indicate that promotion and remuneration are significantly related to employee retention, meaning that the likelihood of employees to continue working in a firm is much higher when they are adequately remunerated and promoted as at when due. It can be seen that these two dimensions of reward system cover both intrinsic and extrinsic rewards, thereby ensuring that the different aspects of employee needs and expectations are met. Interestingly, increased renumeration mostly comes as a function of workbased promotion which emphasizes why these two are deemed as being very important to employees in the Nigerian banking industry. On the other hand, if the promotion and remuneration is not deemed to be leading to job satisfaction at the workplace, then employees are not likely to stay longer in such an organisation.

\section{Conclusion}

This research work has examined the relationship between 
reward system and employee retention in banks in Port Harcourt, Rivers State. It was seen that the dimensions of reward system (promotion and remuneration) as measured against employee retention in banks in Port Harcourt are significantly correlated. The relationship between reward system and employee retention is strong. This result implied that the employees were willingly adjusting to remain with the banks, especially because of the rewards they are getting from the banks that they work for. It is noteworthy to state that the relationship between remuneration and employee retention showed a highly marked correlation. This result implied that the banking industry can keep her workers through improved remuneration. In other words, if the banks want to keep their best talents then they must ensure that they maintain and continuously improve on their remuneration packages for their employees. Therefore, the study concludes that reward system is a key determinant of employee retention within banks in Port Harcourt. positively influences employee retention within an organization.

\section{Recommendations}

Considering the conclusion reached above, the following recommendations are made. Firstly, there should be further empirical research to test the applicability of the findings of this study in other sectors of the Nigerian economy. Secondly, other dimensions of reward system should be tested empirically to validate their relationship with employee retention.

\section{References}

[1] Agwu, M.O. (2013). Impact of Fair Reward System on Employees Job Performance in Nigerian Agip Oil Company Limited Port-Harcourt. British Journal of Education, Society \& Behavioral Science, 3 (1), 47-64.

[2] Ajila, C., \& Abiola A. (2004). Influence of rewards on work performance in an organization. Journal of Social Science, 8 (1), 7-12.

[3] Armstrong, M. (2008). Employee reward management and practice (3rd ed.). New Delhi: Kogan page.

[4] Ax, C., Christer, J., \& Kullvén, H. (2005). DNE - Den Nya Ekonomistyrningen (3rd ed.). Malmö: Liber AB.

[5] A'yuninnisa, R. N., \& Saptoto, R. (2015). The effects of pay satisfaction and affective commitment on turnover intention. International Journal of Research Studies in Psychology, 4 (2), 57-70.

[6] Azasu S. (2009). Rewards and performance of Swedish real estate firms. Compensation and Benefits Review, 41 (4), 19-28.

[7] Babagana, A., \& Dungus, B. (2015). Staff Remuneration and the Performance of Ramat Polytechnic Maiduguri Students from 1995 to 2011 European Journal of Research and Reflection in Management Science, 3 (5) 1-10.

[8] Babangida, M. M., Ibrahim, A. \& Abubakar, B. (2014). Effect of Motivational Incentives on Staff Turnover in Hotel. IOSR
Journal of Business and Management (IOSR-JBM), 16 (3), $36-42$.

[9] Baridam, D. M., \& Nwibere, B. M. (2008). Understanding and Managing Organizational Behaviour. Port Harcourt: Sherbrooke Associates.

[10] Bright, H. (2012). Motivating Organizational Employees. New York: Park View Publishers.

[11] Chaminade, B. (2007). A Retention Checklist: How Do You Rate? Retrieved on 11th December, 2020, from http://www.humanresourcesmagazine.co.au.

[12] Chiboiwa, M. W., Samuel, M. O., \& Chipunza, C. (2010). An Examination of Employee Retention Strategy in a Private organization in Zimbabwe. African Journal of Business Management, 4 (10), 2103-2109.

[13] Cho, S., Woods, R., Jang, S., \& Erdem, M. (2006). Measuring the impact of human resource management practices on hospitality firms' performances. International Journal of Hospitality Management, 25 (2), 262-277.

[14] Edirisooriya, W. A. (2014). Impact of Rewards on Employee Performance: With Special Reference to ElectriCo. Reshaping Management and Economic Thinking through Integrating Eco-Friendly and Ethical Practices Proceedings of the 3rd International Conference on Management and Economics. Faculty of Management and Finance, University of Ruhuna, Sri Lanka.

[15] Ejiofor, P. N. O., \&, Mbachu, A. U. (2001). Imperative of Human Resource Practices in the Ne Millennium. Journal of the Management Sciences, 5 (1), 121-126.

[16] Ejumudo, K. B. O. (2011). Performance Appraisal in the Delta State Civil Service. Journal of Management, 5(2), 21-28.

[17] Erbasi, Ali \& Arat, T. (2012). The effect of financial and nonfinancial incentives on job satisfaction. An examination of food chain premises in Turkey. International Business Research, 5 (10), 136-145.

[18] Farooqui, S., \& Nagendra, A., (2014). The Impact of Person Organization Fit on Job Satisfaction and Performance of the Employees. Procedia Economics and Finance, 11, 122-129.

[19] Frank, F. D., Finnegan, R. P. \& Taylor, C. R. (2004). The Race for Talent: Retaining and Engaging Workers in the 21st Century. Human Resource Planning, 27 (3), 12-25.

[20] Furtado, F., Aquino, G., \& Meira, S. (2009). Incentive Systems in Software Organizations. ICSEA 2009 - The Fourth International Conference on Software Engineering Advances. Porto, Portugal. September, 2009.

[21] Hackman, J. R., \& Oldham, G. R. (1976). Motivation through the design of work: test of a theory. Organizational Behavior and Human Performance, 16 (2), 250-279.

[22] Hafiza, N. S., Shah, S. S., Jamsheed, H., \& Zaman, K. (2011). Relationship Between Rewardsand Employee's Motivation in the Non-Profit Organizations of Pakistan. Business Intelligence Journal, 4 (2), 327-334.

[23] Hameed, A., Ramzan, M., Zubair, H. M. K., Ali, G. \& Arslan, M. (2014). Impact ofCompensation on Employee Performance (Empirical Evidence from Banking Sector of Pakistan). International Journal of Business and Social Science. 5 (2), 302-309. 
[24] Jaghult, B. (2005). Management of Rewards in Organizations. Sollentuna: Non-Stop Communications.

[25] Khan, I., Shahid, M., Nawab, S. \& Wali, S.S. (2013). Influence of intrinsic and extrinsic rewards on employee performance: The banking sector of Pakistan. Academic Research International, 4 (1), 282 - 292.

[26] Lawler, E.E. (2008). Talent: Making People your Competitive Advantage. San Francisco: Jossey-Bass.

[27] Merchant, V.D.S. (2007). Management Control System, performance measurement, Evaluation and Incentive. New York: Financial Times/Prentice.

[28] Milman, A. (2003). Hourly employee retention in small and medium attractions: The Central Florida example. International Journal of Hospitality Management, 22, 17-35.

[29] Milman, A., \& Ricci, P. (2004). Predicting job retention of hourly employees in the lodging industry. Journal of Hospitality and Tourism Management, 11 (1), 23-41.

[30] Mohammad, A. \& Afshan, B. (2014). The impact of incentives on Employees turnover at Pakistan International Container Terminal Limited ("PICT") with respect to the different age brackets. IOSR Journal of Business and Management (IOSR-JBM), 16 (1), 53-60.

[31] Nawab, S., Ahmad, J., \& Shafi, K. (2011). An Analysis of Differences in Work Motivation between Public and Private Sector Organizations. Interdisciplinary Journal of Contemporary Research in Business, 2 (11), 110-127.

[32] Ong, S., \& Teh, H. (2012). Reward System and Performance Within Malaysian Manufacturing Companies, IDOSI Publications, 1Faculty of Economics and Management, University Putra Malaysia, Malaysia.

[33] Osibanjo, A. O., Salau, O. P., Falola, S., \& Hezekiah, O. (2014). Modeling the Relationship between Motivating Factors, Employee' Retention, and Job Satisfaction in the Nigerian Banking Industry. Journal of Management Policies and Practices 2 (2), 63-83.

[34] Jabbar, M. N., \& Hussin, F. (2018). Effect of organizational leadership behavior and empowerment on job satisfaction. Opción, 34 (16), 472-491.

[35] Richard, M., Ryan \& Deci (2010). Intrinsic and Extrinsic Motivations: Class Definitions and New Directions. Contemporary Educational Psychology, 25, 54-67.

[36] Rukhmani, K., Ramesh, M., \& Jayakrishman, J. (2010). Effect of Leadership Styles on organizational Effectiveness. European Journal of Social Sciences, 15 (3), 365-369.

[37] Sajuyigbe, A. S., Bosede, O. O. \& Adeyemi, M. A. (2013). Impact of Reward on Employees Performance in a Selected Manufacturing Companies in Ibadan, Oyo State, Nigeria. International Journal of Arts and Commerce, 2, 2.

[38] Samuel, M. O. (2008). Using Motivational Strategy as Panacea for Employee Retention and Turnover in Selected Public and Private Sector Organizations in Eastern Cape Province of South Africa. Unpublished M.Sc. Thesis, University of Fort Hare.

[39] Sikula, A. E. (2000). Personnel administration and human resources management. Toronto: John Wiley \& Sons, Inc.

[40] Surbhi, S. (2015). Differences between Salaries and Wages.
Retrieved on 24th December, 2020 from http://keydifferences.com/difference-between-salaryandwages.html\#ixzz4IG1CT6Vu

[41] Susskind, A. M., Borchgrevink, C. P., Kacmar, K. M., \& Brymer, R.A. (2000, March). Customer service employees' behavioral intentions and attitudes: An examination of construct validity and a path model. International Journal of Hospitality Management, 19 (1). 53-77.

[42] Walsh, K., \& Taylor, M. (2007). Developing in-house careers and retaining management talent. Cornell Hotel and Restaurant Administration Quarterly, 48 (2), 163-82.

[43] Wang, Y. (2014). Observations on the Organizational Commitment of Chinese Employees: Comparative Studies of State-Owned Enterprises and Foreign-Invested Enterprises. The International Journal of Human Resource Management, 15 (4), 649-664.

[44] Wildes, V. J. (2007). Attracting and retaining food servers: how internal service quality moderates occupational stigma. International Journal of Hospitality Management, 26 (1), 4-19.

[45] Williamson, I. O., Burnett, M. F., \& Bartol, K. M. (2009). The interactive effect of collectivism and organizational rewards on affective organizational commitment. Cross Cultural Management: An International Journal, 16 (1), 28-43. doi: $10.1108 / 13527600910930022$

[46] Kaplan, R. S., \& Atkinson, A. A. (1998). Advanced management accounting (3rd ed.). Upper Saddle River: Prentice-Hall.

[47] Cardy, R. L., \& Lengnick-Hall, M. L. (2011). Will they stay or will they go? Exploring a customer-oriented approach to employee retention. Journal of Business and Psychology, 26 (2), 213-217.

[48] Özutku, H. (2012). The influence of intrinsic and extrinsic rewards on employee results: An empirical analysis in Turkish manufacturing industry. Business and Economics Research Journal, 3 (3), 29-48.

[49] Becker, B., and Huselid, M. (1999), An interview with Mike Losey, Tony Rucci, and Dave Ulrich: three experts respond to HRMJ's special issue on HR strategy in five leading firms, Human Resource Management, 38 (4), 353-65.

[50] Pradhan, R. K., Jena, L. K., \& Pattnaik, R. (2017). Employee Retention Strategies in Service Industries: Opportunities and Challenges. Employees and Employers in Service Organizations, 53-70.

[51] Kaur, K., \& Asdhir, V. (2018). A Study of impact of labour welfare measures on job motivation. International Journal of Management, IT and Engineering, 8 (8), 286-293.

[52] Malinga, K. S., Stander, M., \& Nell, W. (2019). Positive leadership: Moving towards an integrated definition and interventions. Theoretical Approaches to Multi-Cultural Positive Psychological Interventions, 201-228.

[53] Riaz, H., Akhtar, C., \& Aslam, R. (2018). Total rewards and employee performance: Investigating the mediating role of employee motivation in telecom sector. Pakistan Administrative Review, 2 (3), 342-356.

[54] Mabaso, C. M., \& Dlamini, B. I. (2018). Total rewards and its effects on organisational commitment in higher education institutions. SA Journal of Human Resource Management, 16 (1), $1-8$ 
[55] Iqbal, S., Guohao, L., \& Akhtar, S. (2017). Effects of job organizational culture, benefits, salary on job satisfaction ultimately affecting employee retention. Review of Public Administration and Management, 5 (3), 1-7.

[56] Asaari, M. H. A. H., Desa, N. M., \& Subramaniam, L. (2019). Influence of salary, promotion, and recognition toward work motivation among government trade agency employees. International Journal of Business and Management, 14 (4), 48-59.

[57] Wilson, G. (2010). The Effects of External Rewards on
Intrinsic Motivation. $\quad$ Retrieved from http://www.abcbodybuilding.com/ on 23/03/2021.

[58] Sawaneh, I. A., \& Kamara, F. K. (2019). An effective employee retention policy as a way to boost organizational performance. Journal of Human Resource Management, 7 (2), 41-48.

[59] Leidner, D. E., Gonzalez, E., \& Koch, H. (2020). An affordance perspective of enterprise social media and organizational socialization. In Strategic Information Management (pp. 364-402). Routledge. 